\title{
Clinical presentation and hospitalisation duration of 201 coronavirus disease 2019 patients in Abuja, Nigeria
}

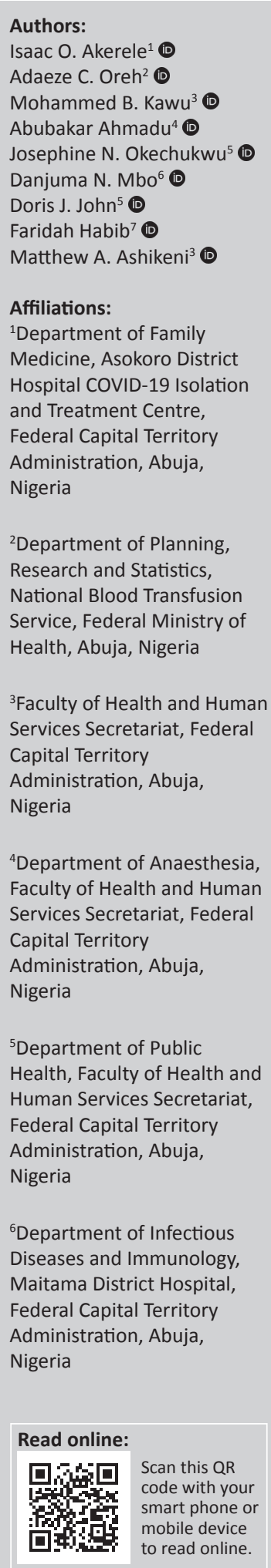

Background: Knowledge of severe acute respiratory syndrome coronavirus 2 (SARS-CoV-2) infection is unfolding. Insights from patient features in different environments are therefore vital to understanding the disease and improving outcomes.

Aim: This study aimed to describe patient characteristics associated with symptomatic presentation and duration of hospitalisation in coronavirus disease 2019 (COVID-19) patients managed in Abuja.

Setting: The study was conducted in Abuja, the Federal Capital Territory, Nigeria.

Methods: This was a retrospective study of 201 COVID-19 patients hospitalised in the Asokoro District Hospital COVID-19 Isolation and Treatment Centre between April 2020 and July 2020. Demographic and clinical data were obtained and outcomes assessed were symptom presentation and duration of hospitalisation.

Results: Patients' median age was 39.3 years (interquartile range [IQR]: 26-52); 65.7\% were male and $33.8 \%$ were health workers. Up to $49.2 \%$ of the patients were overweight or obese, $68.2 \%$ had mild COVID-19 at presentation and the most common symptoms were cough $(38.3 \%)$ and fever (33.8\%). Hypertension (22.9\%) and diabetes mellitus (7.5\%) were the most common comorbidities. The median duration of hospitalisation was 14.4 days (IQR: 9.5-19). Individuals with secondary and tertiary education had higher percentage symptoms presentation $(8.5 \%$ and $34 \%$, respectively), whilst a history of daily alcohol intake increased the length of hospital stay by $129.0 \%$.

Conclusion: Higher educational levels were linked with symptom presentation in COVID-19 patients and that daily alcohol intake was significantly associated with longer hospital stay. These findings highlight the importance of public education on COVID-19 for symptom recognition, early presentation and improved outcomes.

Keywords: coronavirus disease 2019; COVID-19; SARS-CoV-2; presentation; duration of hospitalisation; hospital stay; patient education; Abuja; Nigeria.

\section{Introduction}

Since December 2019 when the coronavirus disease 2019 (COVID-19) was first reported from Wuhan, China, by the World Health Organization (WHO), numbers of infected cases have steadily continued to rise globally. As at the time of writing, over 107 million cases have been reported across the world, with more than 2 million deaths. ${ }^{1}$ In Nigeria, the first case was identified on 27 February 2020 and since then, there have been over 140000 confirmed cases, 114635 patients have been discharged and 1673 deaths have been recorded from the virus. ${ }^{2}$

Whilst Lagos State has been the epicentre of the outbreak in Nigeria (36.9\% of the confirmed cases), Abuja the Federal Capital Territory (FCT) is the state with the second highest number of infections, accounting for $12.7 \%$ of the confirmed cases in the country. ${ }^{2}$

The severe acute respiratory syndrome coronavirus 2 (SARS-CoV-2) is transmitted via respiratory droplets, with current epidemiological evidence suggesting an incubation period of 5-14 days. ${ }^{3,4}$

${ }^{7}$ Department of Family Medicine, Nisa Premier Hospital, Abuja, Nigeria

Corresponding author: Adaeze Oreh, azoreh@yahoo.com

Dates: Received: 20 Feb. 2021|Accepted: 17 Aug. 2021|Published: 27 Oct. 2021

How to cite this article: Akerele IO, Oreh AC, Kawu MB, et al. Clinical presentation and hospitalisation duration of 201 coronavirus disease 2019 patients in Abuja, Nigeria. Afr J Prm Health Care Fam Med. 2021;13(1), a2940. https://doi.org/10.4102/phcfm.v13i1.2940

Copyright: @ 2021. The Authors. Licensee: AOSIS. This work is licensed under the Creative Commons Attribution License. 
Clinical presentation is said to be more predominant in males, with more common symptoms such as fever, dry cough, shortness of breath, headache, fatigue, sore throat, loss of smell, loss of taste and myalgia; in addition to less common symptoms such as nausea, vomiting and diarrhoea. ${ }^{3}$ Additional laboratory and radiographic findings include prolonged prothrombin time, lymphopenia and pulmonary infiltrates on chest radiography. ${ }^{5}$ The absence of symptoms as outlined here, however does not preclude viral transmission in asymptomatic and pre-symptomatic carriers.

The national strategy to fight COVID-19 which was adopted by Abuja, the FCT was the 'Test, Trace, Isolate and Treat'. Asokoro District Hospital was the second hospital after the University of Abuja Teaching Hospital, Gwagwalada, designated for the management of COVID-19 cases in Abuja that received a significant number of confirmed cases of COVID-19. To adequately implement a successful response to COVID-19 in Nigeria, a clear understanding of the demographic and clinical profiles of COVID-19 in the local environment is needed. ${ }^{6}$

Several studies documenting the spectrum of clinical characteristics of COVID-19 patients in South-West Nigeria are available. ${ }^{6,78}$ However, evidence from Northern Nigeria is not readily available. As the COVID-19 pandemic continues to spread rapidly, with countries recording new waves of heightened infections, it is pertinent that locally derived evidence adds to the body of knowledge and is used to strengthen national and global public health responses to the pandemic.

This study examines the sociodemographic and clinical characteristics of the first 201 laboratory-confirmed polymerase chain reaction (PCR) positive COVID-19 patients treated at Asokoro District Hospital in Abuja Nigeria. Furthermore, it relates these features to outcomes such as symptom presentation and the duration of hospitalisation for COVID-19 and identifies lessons to reduce transmission of the virus and improve patient outcomes.

\section{Methodology}

\section{Study design}

This was a retrospective study of 201 cases managed at the Asokoro COVID-19 Isolation and Treatment Centre in Asokoro District Hospital, Abuja, between 10 April 2020 and 31 July 2020. This study forms part of the Asokoro District Hospital COVID-19 Clinicopathological Profile Project, which investigates the clinical, laboratory, radiologic and pathologic presentation of COVID-19 patients managed at the hospital.

\section{Study settings}

The study was conducted on COVID-19 patients treated at the COVID-19 Isolation and Treatment centre in Asokoro District Hospital, Abuja, the FCT, North-Central Nigeria. According to the 2018 National Demographic and Health Survey, Abuja has a population of over 3.5 million. ${ }^{9,10}$ The
Asokoro District Hospital, being one of the foremost public infectious disease hospitals in Nigeria FCT, was the second facility in Abuja designated to isolate and treat COVID-19 patients with funding support from the WHO, the United States Centers for Disease Control and Prevention (US CDC), and African Field Epidemiology Network (AFENET). It has a 60-bed admission treatment facility with a female to male bed space ratio of 20:40, a dedicated biosafety laboratory, emergency operations centre, and a biosecurity unit.

The process for admission entailed identification of laboratoryconfirmed SARS-CoV-2 individuals by a remote triage team, coordinated by the State Epidemiologist and Department of Public Health followed by transportation of the confirmed individuals to the facility in a COVID-19 evacuation ambulance. On arrival at the isolation facility, consent was obtained and baseline clinical assessments were conducted after which a bedspace was allocated to individuals who accepted inpatient care. Discharge from the isolation facilities during the period of the study was based on the WHO criteria: (1) three days after resolution of symptoms and (2) two negative Reverse transcription polymerase chain (RT-PCR) SARS-CoV-2 results, at least $24 \mathrm{~h}$ apart. ${ }^{11,12}$

\section{Study data}

Case records of hospitalised and outpatient laboratoryconfirmed COVID-19 cases seen between 10 April 2020 and 31 July 2020 were obtained. Inclusion criterion for the selected records was a laboratory-confirmed SARS-CoV-2 infection. A laboratory-confirmed case of the SARS-CoV-2 virus was defined as a positive result on high-throughput sequencing or real-time RT-PCR assay of a nasopharyngeal swab and oropharyngeal specimens based on the WHO guidelines. ${ }^{13}$

\section{Data collection tool}

Patients' demographic information, clinical symptoms and signs, comorbidities, laboratory and radiographic findings, in addition to information on the duration of hospitalisation till a negative COVID-19 test result were recorded. These medical records were then independently reviewed by a team of experienced clinicians who in addition to having 15 years' of experience had also received extensive training in quality data management and abstracted data of cases seen during the study period. The abstracted data were collected from electronic medical records and entered in a Microsoft Excel spreadsheet (2019) under the coordination of the Research Unit of the FCT Health and Human Services Secretariat. Double entry was required for all variables and the data were reconciled by a third party. When missing data were encountered, requests for clarification were sent to the Case Manager at the COVID-19 treatment centre who subsequently contacted the attending clinicians or verified from the source documents. Of a total of 206 discharged cases as at 31 July 2020 (Nigeria Centre for Disease Control [NCDC] update week 31), ${ }^{14} 5$ cases with missing or incomplete records on demographic and/or clinical information were excluded. There were no patient mortalities recorded. 


\section{Study variables}

The study outcomes of interest were the duration of hospitalisation (measured in days) and self-reported presence of symptoms from the time of laboratory diagnosis of COVID-19 and subsequent isolation at a health facility. Furthermore, the self-reported presence of comorbidities was assessed categorically: no comorbidity, one comorbidity and two or more comorbidities. The COVID-2019 severity was defined as mild, moderate or severe according to the US CDC definitions. ${ }^{15}$ Mild illness was defined as individuals who had any of the various signs and symptoms of COVID-19 (such as fever, cough, sore throat, malaise, headache, muscle pain, nausea, vomiting, diarrhoea, loss of taste and smell), but who did not have shortness of breath, dyspnoea or abnormal chest imaging. Moderate COVID-19 described individuals who showed evidence of lower respiratory disease during clinical assessment or imaging and who had an oxygen saturation $\left(\mathrm{SpO}_{2}\right) \geq 94 \%$ on room air at sea level. Severe illness was defined as individuals who had $\mathrm{SpO}_{2}<94 \%$ on room air at sea level, a ratio of arterial partial pressure of oxygen to fraction of inspired oxygen $(\mathrm{PaO} 2 / \mathrm{FiO} 2)$ $<300$ millimetre of mercury $(\mathrm{mmHg})$, respiratory frequency $>30$ breaths $/ \mathrm{min}$ or lung infiltrates $>50 \% .^{15}$

\section{Statistical analysis}

Statistical analysis was performed using International Business Machine Corporation (IBM) Statistical Package for the Social Sciences (SPSS) Statistics for Windows, version 24.0. (Armonk, NY: IBM Corp). Demographic information, medical history and COVID-19 symptoms were analysed using descriptive statistics. Pearson's Chi-square test was used to determine an association between the categorical data. Bivariate and multivariate logistic regression models were used to investigate the association between demographic information, comorbidities (self-reported and determined following clinical assessment), the presence or absence of COVID-19 symptoms , and duration of hospitalisation. A logistic regression model was used to investigate the association between demographic information, number of comorbidities (none, 1 comorbidity and $\geq 2$ comorbidities), symptomatic presentation and duration of hospitalisation ( $\leq 14$ days and $>14$ days). Tests of normality were used to assess continuous variables. A $p$-value $<0.05$ was considered statistically significant and tests were 2 -tailed with confidence levels of $95 \%$.

\section{Results}

\section{Demographic and clinical characteristics of patients}

A total of 201 cases were analysed for this study, with a mean age of 39.3 years (standard deviation [s.d.] \pm 13.1 ) and $65.7 \%$ $(n=132)$ of the patients male.

Approximately one-third of the patients (33.3\%) presented with one or more comorbidities (Figure 1). Hypertension (22.9\%), diabetes mellitus (7.5\%), peptic ulcer disease $(5.5 \%)$ and asthma $(4.0 \%)$ were the most common comorbidities, whereas comorbidities such as liver disease, stroke and mental health disorders were less common. About $68.2 \%$ of the patients presented with a mild form of the disease and only $26.8 \%$ were asymptomatic at presentation. Out of all the patients studied, only 3.0\% had severe disease and were in respiratory distress. The most common symptoms at presentation were: cough $(38.3 \%)$, fever $(33.8 \%)$, fatigue $(26.9 \%)$, poor appetite $(26.9 \%)$ and headache (25.4\%). Insomnia (3.1\%) and nausea (0.5\%) were the least common symptoms. The mean duration of hospitalisation was 14.4 days (s.d. \pm 4.9 ), with median duration of 13 days and $99 \%$ of the patients were discharged following management with $1 \%(n=2)$ referral following diabetic complication of grade 4 diabetic foot ulcer requiring further specialist care than the facility could provide at that time and personal preference for another facility, respectively.

Overweight and obesity were observed in $49.2 \%(n=99)$ of the patients, $2.0 \%$ had a known history of tuberculosis, $86.5 \%$ had a history of Bacillus Calmette-Guérin (BCG) vaccination, $12.9 \%$ had a recent travel history and the location of exposure was unknown in $69.7 \%$ of the patients. However, for those patients who knew their location of exposure $(n=61)$, the non-hospital workplace $(34.4 \%)$ was the commonest location of exposure, closely followed by home $(32.8 \%)$ and hospital $(24.6 \%)$. International travel was observed in only $15.4 \%$ of the patients who gave a history of recent travel, as domestic travel accounted for $84.6 \%$ of the patients' travels (Figure 2).

\section{Association between the COVID-19 patient demographic characteristics, comorbidity and symptomatic presentation}

The association between patient demographic characteristics, comorbidity and symptomatic presentation is illustrated in Table 1. Age $(p=0.046)$, occupation $(p=0.015)$, employment status $(p=0.004)$ and education $(p=0.001)$ were significantly

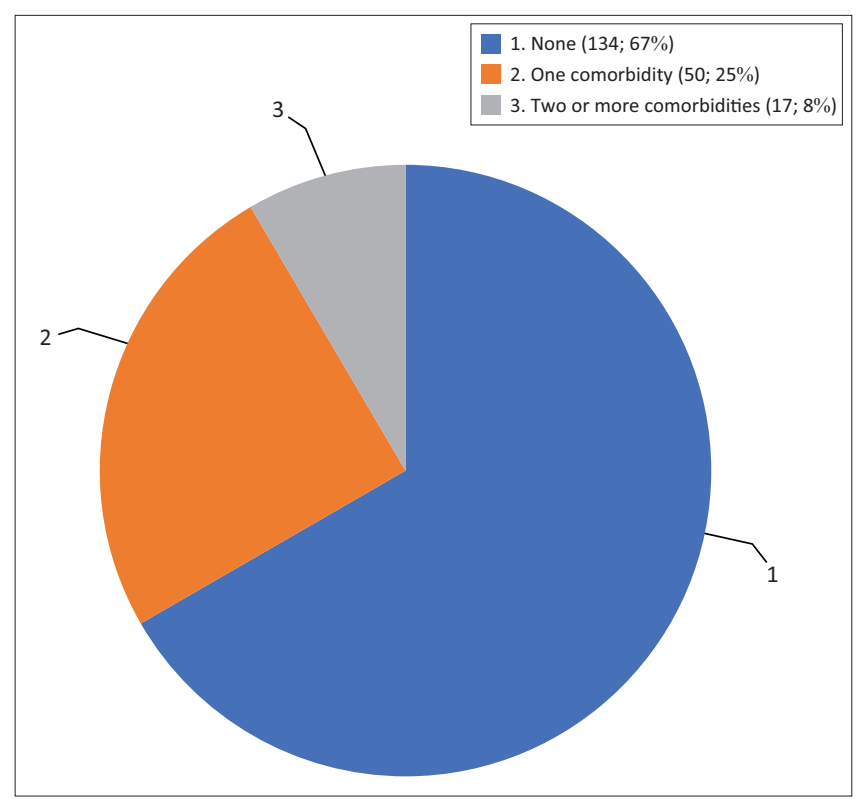

FIGURE 1: Number of comorbidities in patients admitted at Asokoro District Hospital Coronavirus Disease 2019 Isolation and Treatment Centre. 


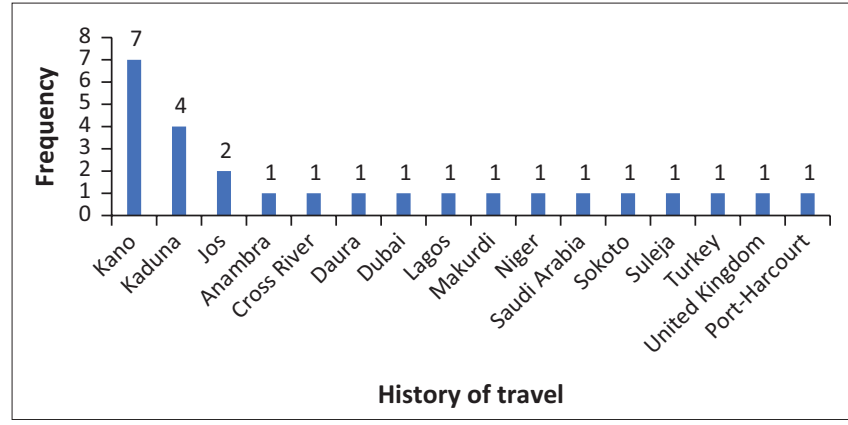

FIGURE 2: Chart depicting domestic and international travel history of COVID-19 patients managed in Asokoro, Abuja.

TABLE 1: Chi-square analysis to demonstrate the association between patient demographic factors and symptomatic COVID-19.

\begin{tabular}{|c|c|c|c|c|c|c|}
\hline \multirow[t]{3}{*}{ Variables } & \multicolumn{4}{|c|}{ Symptomatic presentation } & \multirow[t]{3}{*}{$\chi^{2}$} & \multirow[t]{3}{*}{$p$} \\
\hline & \multicolumn{2}{|c|}{$\begin{array}{l}\text { Asymptomatic } \\
(n=54)\end{array}$} & \multicolumn{2}{|c|}{$\begin{array}{l}\text { Symptomatic } \\
\quad(n=147)\end{array}$} & & \\
\hline & $n$ & $\%$ & $n$ & $\%$ & & \\
\hline Age group (years) & & & & & 11.312 & $0.046^{*}$ \\
\hline$<20$ & 7 & 13.0 & 4 & 2.7 & - & - \\
\hline $20-29$ & 11 & 20.4 & 24 & 16.3 & - & - \\
\hline $30-39$ & 16 & 29.5 & 38 & 25.9 & - & - \\
\hline $40-49$ & 11 & 20.4 & 36 & 24.5 & - & - \\
\hline $50-59$ & 7 & 13.0 & 36 & 24.5 & - & - \\
\hline$\geq 60$ & 2 & 3.7 & 9 & 6.1 & - & - \\
\hline Gender & & & & & 0.681 & 0.409 \\
\hline Female & 33 & 61.1 & 99 & 67.3 & - & - \\
\hline Male & 21 & 38.9 & 48 & 32.7 & - & - \\
\hline Occupation & & & & & 5.976 & $0.015^{*}$ \\
\hline Healthcare workers & 11 & 20.4 & 57 & 38.8 & - & - \\
\hline Non-healthcare workers & 43 & 79.6 & 90 & 61.2 & - & - \\
\hline Employment status & & & & & 8.504 & $0.004 *$ \\
\hline Employed & 46 & 85.2 & 142 & 96.6 & - & - \\
\hline Unemployed & 8 & 14.8 & 5 & 3.4 & - & - \\
\hline Education & & & & & 29.012 & $<0.001 *$ \\
\hline No formal education & 8 & 14.8 & 7 & 4.8 & & - \\
\hline Primary & 8 & 14.8 & 3 & 2.0 & - & - \\
\hline Secondary & 16 & 29.7 & 23 & 15.6 & - & - \\
\hline Tertiary & 22 & 40.7 & 114 & 77.6 & - & - \\
\hline Comorbidity & & & & & 4.103 & 0.129 \\
\hline None & 42 & 77.7 & 92 & 62.6 & - & - \\
\hline One & 9 & 16.7 & 41 & 27.9 & - & - \\
\hline Two or more & 3 & 5.6 & 14 & 9.5 & - & - \\
\hline
\end{tabular}

*, Significant at $p<0.05$

associated with the presentation of symptoms in patients. The relationship between possible risk factors such as body mass index (BMI), history of travel, history of tuberculosis and BCG vaccination, contact history, daily alcohol intake, smoking and patient symptoms were assessed. Only daily alcohol intake showed any association with symptomatic patient presentation $(p=0.024)$.

Logistic regression was subsequently carried out to identify factors predictive of symptomatic COVID-19 presentation (Table 2). Patients with secondary and tertiary education showed significantly higher odds of presenting with symptoms of COVID-19 (odds ratio [OR]:1.085; with 95\% confidence interval $[\mathrm{CI}]: 1.020-1.374 ; p=0.001)$ and (OR: 1.340; with $95 \%$ CI: $1.137-1.847 ; p=0.021$ ), respectively, which translated to $8.5 \%$ and $34 \%$ increments, respectively, compared with patients with no formal education.

\section{Association between the COVID-19 patient demographic characteristics and comorbidity and duration of hospitalisation}

Table 3 illustrates the association between patient demographic characteristics and the duration of hospitalisation for COVID-19. Occupation $(p<0.001)$, education $(p=0.001)$ and comorbidity $(p=0.001)$ were significantly associated with the duration of hospitalisation. In Table 4 , a significant association was demonstrated between BMI $(p<0.001)$, location of exposure $(p=0.020)$, daily alcohol intake $(p=0.001)$, contact history $(p=0.014)$, and the duration of hospitalisation for COVID-19. However, following logistic regression analysis (Table 5), only patients with a history of daily alcohol intake showed significantly higher odds of having a lengthened duration of hospitalisation (OR: 2.288; with 95\% CI: 2.103$2.804 ; p=0.017)$, which translated to a $129 \%$ increment in length of hospital stay.

\section{Discussion}

This study aimed at identifying the demographic characteristics and clinical profiles of a cohort of COVID-19 patients managed at the Asokoro COVID-19 Isolation and Treatment facility in Abuja, the FCT, Nigeria.

The study's findings revealed a mean age of just below 40 years and that majority of patients were male. About 7 out of every 10 patients had symptoms present, approximately a third had one or more comorbidities and the mean duration of hospitalisation recorded was about 2 weeks. Higher levels of education were significantly associated with symptomatic presentation, whilst daily alcohol intake was significantly associated with the duration of hospitalisation.

The lower mean age recorded in this study is reflective of the younger population age in Nigeria compared with reports on the COVID-19 pandemic from the United Kingdom, Italy, United States and China. ${ }^{9,10,16,17,18}$ One major finding from our study is the preponderance of COVID-19 in economically active age groups, which points at the possible role of socioeconomic or work-related activities in the transmission of the infection.

In this study, nearly 7 out every 10 patients had no idea where they may have been exposed to the SARS-CoV-2 virus. For those who knew their location of exposure, the workplace and the home accounted for about $67 \%$ and hospitals for healthcare workers accounted for a quarter of infections. This finding tallies with reports from research led by the Harvard T.H. Chan School of Public Health, which documented the substantial role of workplaces in facilitating spread of the disease during the early stages of the outbreak in six Asian countries. ${ }^{19}$ The Harvard study similarly demonstrated that non-hospital work-related transmissions were considerably more frequent. This emphasises the importance of ensuring strict adherence to COVID-19 preventive protocols such as wearing of face masks, physical distancing measures, and 
TABLE 2: Logistic regression model demonstrating the association between patient characteristics and symptomatic presentation.

\begin{tabular}{|c|c|c|c|c|}
\hline \multirow[t]{2}{*}{ Variables } & \multirow[t]{2}{*}{$p$} & \multirow[t]{2}{*}{ Odds ratio } & \multicolumn{2}{|c|}{$95 \% \mathrm{Cl}$ for odd ratio } \\
\hline & & & Lower & Upper \\
\hline \multicolumn{5}{|l|}{ Age } \\
\hline$<20$ & 1.000 & (Reference) & - & - \\
\hline $20-29$ & 0.813 & 0.732 & 0.056 & 9.652 \\
\hline 30-39 & 0.828 & 0.821 & 0.138 & 4.880 \\
\hline $40-49$ & 0.775 & 0.780 & 0.141 & 4.316 \\
\hline $50-59$ & 0.791 & 1.271 & 0.217 & 7.452 \\
\hline$\geq 60$ & 0.749 & 1.348 & 0.216 & 8.407 \\
\hline \multicolumn{5}{|l|}{ Occupation } \\
\hline Healthcare worker & 1.000 & (Reference) & - & - \\
\hline $\begin{array}{l}\text { Non-healthcare } \\
\text { worker }\end{array}$ & 0.733 & 1.169 & 0.477 & 2.867 \\
\hline \multicolumn{5}{|l|}{ Employment status } \\
\hline Employed & 1.000 & (Reference) & - & - \\
\hline Unemployed & 0.549 & 1.778 & 0.271 & 11.671 \\
\hline \multicolumn{5}{|l|}{ Education } \\
\hline No formal education & 1.000 & (Reference) & - & - \\
\hline Primary & 0.088 & 0.299 & 0.074 & 1.198 \\
\hline Secondary & $0.001 *$ & 1.085 & 1.020 & 1.374 \\
\hline Tertiary & $0.021 *$ & 1.340 & 1.137 & 1.847 \\
\hline \multicolumn{5}{|l|}{ Daily alcohol intake $\dagger$} \\
\hline No & 1 & (Reference) & - & - \\
\hline Yes & 0.112 & 2.053 & 0.846 & 4.985 \\
\hline
\end{tabular}

frequent hand washing and disinfection of surfaces in workplaces. ${ }^{20}$ The proportion of health workers infected (33.8\%) in this study is substantially greater than earlier reports from Nigeria $(9 \%)^{21}$ and has considerable implications for the already stretched healthcare workforce in fragile, underresourced health systems. Further studies assessing infection rates with health facility preparedness in terms of availability of personal protective equipment (PPE), facility design, space management and cross-ventilation are therefore warranted. Space and ventilation issues are also relevant to COVID-19 transmission in non-hospital workplace environments. ${ }^{22}$

As this study was conducted during restrictions on places of worship and social gatherings, these accounted for less than $10 \%$ of patients. However, lapses in adherence to preventive measures always leave household members vulnerable, as nearly $33 \%$ of the patients were infected in their homes. Male predominance in presentation has similarly been reported in prior studies in Nigeria and globally. ${ }^{20}$ As women make up a substantial proportion of the workforce in Nigeria, it is worth mentioning the likely impact of the significant differences in membrane-bound angiotensin-converting enzyme 2 (mACE2) expression between males and females in the presentation of COVID-19.23,24

International travel restrictions were in place during the study but in the less than $15 \%$ of the patients who reported a history of travel, more than three-quarters of those trips were between states (Figure 2). It is therefore paramount that travellers continue to adhere to infection prevention measures and the public remains vigilant to the fact that a pandemic is ongoing, as anyone could be infected, especially
TABLE 3: Chi-square analysis demonstrating the association between patient demographic factors, comorbidity and duration of hospitalisation.

\begin{tabular}{|c|c|c|c|c|c|c|}
\hline \multirow[t]{3}{*}{ Variables } & \multicolumn{4}{|c|}{ Duration of hospitalisation (days) } & \multirow[t]{3}{*}{$\chi^{2}$} & \multirow[t]{3}{*}{$p$} \\
\hline & \multicolumn{2}{|c|}{$\leq 14(n=135)$} & \multicolumn{2}{|c|}{$>14(n=66)$} & & \\
\hline & $n$ & $\%$ & $n$ & $\%$ & & \\
\hline Age group (years) & & & & & 9.521 & 0.090 \\
\hline$<20$ & 6 & 4.4 & 5 & 7.5 & - & - \\
\hline $20-29$ & 17 & 12.6 & 18 & 27.3 & - & - \\
\hline 30-39 & 36 & 26.7 & 18 & 27.3 & - & - \\
\hline $40-49$ & 35 & 25.9 & 12 & 18.2 & - & - \\
\hline $50-59$ & 32 & 23.7 & 11 & 16.7 & - & - \\
\hline$\geq 60$ & 9 & 6.7 & 2 & 3.0 & - & - \\
\hline Gender & & & & & 3.202 & 0.074 \\
\hline Male & 83 & 61.5 & 49 & 74.2 & - & - \\
\hline Female & 52 & 38.5 & 17 & 25.8 & - & - \\
\hline Occupation & & & & & 15.317 & $<0.001 *$ \\
\hline Healthcare workers & 58 & 43.0 & 10 & 15.2 & - & - \\
\hline Non-healthcare workers & 77 & 57.0 & 56 & 84.8 & - & - \\
\hline Education & & & & & 17.391 & $0.001 *$ \\
\hline No formal education & 7 & 5.2 & 8 & 12.1 & - & - \\
\hline Primary & 4 & 3.0 & 7 & 10.6 & - & - \\
\hline Secondary & 20 & 14.8 & 19 & 28.8 & - & - \\
\hline Tertiary & 104 & 77.0 & 32 & 48.5 & - & - \\
\hline Comorbidity & & & & & 13.430 & $0.001 *$ \\
\hline None & 79 & 58.5 & 55 & 83.3 & - & - \\
\hline One & 40 & 29.6 & 10 & 15.2 & - & - \\
\hline Two or more & 16 & 11.9 & 1 & 1.5 & - & - \\
\hline
\end{tabular}

*, Significant at $p<0.05$.

given the fact that infections could be transmitted by asymptomatic or pre-symptomatic individuals.

Approximately $30 \%$ of the patients were asymptomatic at admission, which is almost double the number reported by other Nigerian researchers in the early phase of the pandemic. ${ }^{6}$ Nigeria's Presidential Task Force on COVID-19 mandated isolation and treatment of positively tested cases in designated centres, which ensured that individuals who tested positive but may not have experienced any symptoms were thus admitted for treatment. Whilst earlier studies from Hong Kong and South Korea reported lower rates of asymptomatic cases in treatment centres, asymptomatic cases reported from South-West Nigeria were up to $60 \%{ }^{7,25,26}$ However, patients' mean age and proportion of patients with comorbidities in our study were similar to those reported from Lagos State. ${ }^{7}$

Cough, fever and fatigue were the most predominant symptoms reported in this study, similar to findings from Zhejiang province in China. ${ }^{27}$ Our finding of significant association between higher levels of education and presentation of symptoms in patients may account for some differences in the reporting of symptoms. This highlights the importance of risk communication and education of the public via multiple channels on transmission and symptoms of COVID-19 to heighten public awareness. It is likely that higher levels of education expose individuals to more sources of information on COVID-19, thus enabling them to report symptoms more readily than those with lower levels of education. This is especially important, as any of the most common symptoms 
TABLE 4: Chi-square analysis demonstrating the association between likely patient risk factors and duration of hospitalisation.

\begin{tabular}{|c|c|c|c|c|c|c|}
\hline \multirow[t]{3}{*}{ Variables } & \multicolumn{4}{|c|}{ Duration of hospitalisation (days) } & \multirow[t]{3}{*}{$\chi^{2}$} & \multirow[t]{3}{*}{$p$} \\
\hline & \multicolumn{2}{|c|}{$\leq 14(n=135)$} & \multicolumn{2}{|c|}{$>14(n=66)$} & & \\
\hline & $n$ & $\%$ & $n$ & $\%$ & & \\
\hline $\begin{array}{l}\text { Body mass } \\
\text { index (BMI) }\end{array}$ & & & & & 33.696 & $<0.001^{*}$ \\
\hline Normal & 51 & 37.8 & 46 & 69.7 & - & - \\
\hline Obese & 32 & 23.7 & 5 & 7.6 & - & - \\
\hline Overweight & 52 & 38.5 & 10 & 15.2 & - & - \\
\hline Underweight & 0 & 0.0 & 5 & 7.6 & - & - \\
\hline $\begin{array}{l}\text { History of } \\
\text { tuberculosis }\end{array}$ & & & & & 3.290 & 0.105 \\
\hline No & 134 & 99.3 & 63 & 95.5 & - & - \\
\hline Yes & 1 & 0.7 & 3 & 4.5 & - & - \\
\hline $\begin{array}{l}\text { History of BCG } \\
\text { vaccination }\end{array}$ & & & & & 3.268 & 0.659 \\
\hline No & 7 & 5.2 & 6 & 9.1 & - & - \\
\hline Yes & 127 & 94.8 & 60 & 90.9 & - & - \\
\hline History of travel & & & & & 0.058 & 0.810 \\
\hline No & 117 & 86.7 & 58 & 87.9 & - & - \\
\hline Yes & 18 & 13.3 & 8 & 12.1 & - & - \\
\hline $\begin{array}{l}\text { Location of } \\
\text { exposure }\end{array}$ & & & & & 11.680 & $0.020 *$ \\
\hline Not known & 85 & 63.0 & 55 & 83.3 & - & - \\
\hline Workplace & 16 & 11.8 & 5 & 7.6 & - & - \\
\hline Home & 15 & 11.1 & 5 & 7.6 & - & - \\
\hline Hospital & 15 & 11.1 & 0 & 0.0 & - & - \\
\hline Others $\dagger$ & 4 & 3.0 & 1 & 1.5 & - & - \\
\hline Smoking status: & & & & & 0.576 & 0.479 \\
\hline No & 130 & 96.3 & 62 & 93.9 & - & - \\
\hline Yes & 5 & 3.7 & 4 & 6.1 & - & - \\
\hline $\begin{array}{l}\text { Daily alcohol } \\
\text { intake§ }\end{array}$ & & & & & 10.273 & $0.001^{*}$ \\
\hline No & 90 & 66.7 & 58 & 87.9 & - & - \\
\hline Yes & 45 & 33.3 & 8 & 12.1 & - & - \\
\hline Contact history & & & & & 10.665 & $0.014 *$ \\
\hline Not known & 88 & 65.2 & 56 & 84.9 & - & - \\
\hline $\begin{array}{l}\text { Confirmed } \\
\text { patient }\end{array}$ & 12 & 8.8 & 0 & 0.0 & - & - \\
\hline Colleague & 9 & 6.7 & 2 & 3.0 & - & - \\
\hline Relative & 26 & 19.3 & 8 & 12.1 & - & - \\
\hline
\end{tabular}

BCG, Bacillus Calmette-Guérin.

Body mass index (BMI) values ${ }^{36}$ : Underweight $=<18.5 \mathrm{~kg} / \mathrm{m}^{2}$, normal weight $=18.5 \mathrm{~kg} / \mathrm{m}^{2}$

$-24.9 \mathrm{~kg} / \mathrm{m}^{2}$, overweight $=25 \mathrm{~kg} / \mathrm{m}^{2}-34.9 \mathrm{~kg} / \mathrm{m}^{2}$, Obese $=>35 \mathrm{~kg} / \mathrm{m}^{2}$.

$*$, Significant at $p<0.05$

$\dagger$, Place of worship, police station and social gatherings; $\$$, anyone who has smoked at least 100 cigarettes in his or her lifetime and who now smokes every day OR anyone who has smoked at least 100 cigarettes in his or her lifetime but who had quit smoking at the time of interview (every-day smoker or former smoker) ${ }^{39} ; \S$, anyone who consumes one or more alcoholic drinks daily. ${ }^{40}$

identified in our study could easily be passed off as symptoms of flu, malaria and even allergies. In this study, comorbidity was not significantly associated with symptomatic presentation following logistic regression, at variance with findings reported from Lagos, South-West Nigeria. ${ }^{7}$

The median duration of hospitalisation in this study was about 14 days, less than that reported by the NCDC, where the median length of stay of 111 patients was 19 days. ${ }^{21}$ However, both durations are within the range reported from studies outside of China (4-21 days), although lower in range compared with findings documented from China (4-53 days). ${ }^{28}$ These variations in duration of hospitalisation may be because of the differences between the Chinese National Health Commission management guidelines and the NCDC
TABLE 5: Logistic regression model demonstrating the association between patient characteristics and duration of hospitalisation.

\begin{tabular}{|c|c|c|c|c|}
\hline \multirow[t]{2}{*}{ Variables } & \multirow[t]{2}{*}{$p$} & \multirow[t]{2}{*}{ Odds ratio } & \multicolumn{2}{|c|}{$95 \% \mathrm{Cl}$ for odd ratio } \\
\hline & & & Lower & Upper \\
\hline \multicolumn{5}{|l|}{ Occupation } \\
\hline Healthcare workers & 1.000 & (Reference) & - & - \\
\hline Non-healthcare workers & 0.081 & 0.420 & 0.159 & 1.112 \\
\hline \multicolumn{5}{|l|}{ Education } \\
\hline No formal education & 1.000 & (Reference) & - & - \\
\hline Primary & 0.859 & 0.881 & 0.218 & 3.564 \\
\hline Secondary & 0.584 & 1.512 & 0.345 & 6.624 \\
\hline Tertiary & 0.749 & 1.178 & 0.431 & 3.221 \\
\hline \multicolumn{5}{|l|}{ Comorbidity } \\
\hline None & 1.000 & (Reference) & - & - \\
\hline One & 0.083 & 6.698 & 0.777 & 57.712 \\
\hline Two or more & 0.121 & 6.054 & 0.623 & 58.790 \\
\hline \multicolumn{5}{|l|}{ Body mass index (BMI) } \\
\hline Normal & 1.000 & (Reference) & - & - \\
\hline Obese & 0.999 & 0.000 & 0.000 & - \\
\hline Overweight & 0.999 & 0.000 & 0.000 & - \\
\hline Underweight & 0.999 & 0.000 & 0.000 & - \\
\hline \multicolumn{5}{|l|}{ Location of exposure } \\
\hline Not known & 1.000 & (Reference) & - & - \\
\hline Workplace & 0.942 & 1.126 & 0.046 & 27.611 \\
\hline Home & 0.709 & 1.987 & 0.054 & 73.352 \\
\hline Hospital & 0.892 & 1.293 & 0.032 & 51.729 \\
\hline Others $\dagger$ & 0.998 & 0.000 & 0.000 & - \\
\hline \multicolumn{5}{|l|}{ Daily alcohol intake: } \\
\hline No & 1.000 & (Reference) & - & - \\
\hline Yes & $0.017^{*}$ & 2.288 & 2.103 & 2.804 \\
\hline \multicolumn{5}{|l|}{ Contact history } \\
\hline Not known & 1.000 & (Reference) & - & - \\
\hline Confirmed patient & 0.747 & 1.829 & 0.047 & 71.517 \\
\hline Colleague & 0.998 & 0.000 & 0.000 & - \\
\hline Relative & 0.671 & 0.592 & 0.053 & 6.657 \\
\hline \multicolumn{5}{|c|}{$\mathrm{Cl}$, confidence interval. } \\
\hline \multicolumn{5}{|c|}{$\begin{array}{l}\text { Body mass index values }{ }^{36}: \text { Underweight }=<18.5 \mathrm{~kg} / \mathrm{m}^{2} \text {, normal weight }=18.5 \mathrm{~kg} / \mathrm{m}^{2} \\
24.9 \mathrm{~kg} / \mathrm{m}^{2} \text {, overweight }=25.0 \mathrm{~kg} / \mathrm{m}^{2}-34.9 \mathrm{~kg} / \mathrm{m}^{2}, \text { obese }=>35.0 \mathrm{~kg} / \mathrm{m}^{2}-34.9 \mathrm{~kg} / \mathrm{m}^{2} . \\
* \text {, Significant at } p<0.05 .\end{array}$} \\
\hline
\end{tabular}

and WHO guidelines used in Nigeria, such as the use of traditional Chinese medicine for COVID-19, in addition to timing of the pandemic across countries. ${ }^{11,12,21,29,30}$

Another significant finding from this study was the association between self-reported daily alcohol intake and longer duration of hospitalisation. Several authors have documented the effect of alcohol on both increasing susceptibility to infection and its negative impact on nearly all lung cells and the integrity of the lung barrier function. ${ }^{31,32}$ In fact, heavy alcohol use was acknowledged as a risk factor for poor outcomes during the influenza pandemic of $1918 .^{31,33}$ Despite this, the effect of alcohol on outcomes in the present COVID-19 pandemic has not been reported much by researchers and therefore given the increased propensity for alcohol use during periods of stress, ${ }^{34,35}$ this finding has important implications for the content of public health advisory as escalating COVID-19 infections are recorded in various locations.

In our study, nearly half of the patients studied were overweight or obese. However, this was not found to be significantly 
associated with symptom presentation or duration of hospitalisation. The US CDC and various research studies report that adults with excess weight are at a greater risk of illness severity, hospitalisation, impaired immune function, ventilation difficulties and death from COVID-19.36,37 This study's failure to demonstrate significant associations between obesity, overweight and patient outcomes may require further investigation in larger cohorts of COVID-19 patients.

In addition, despite hypertension and diabetes mellitus being the most frequently observed comorbidities, similar to reports from Lagos State and China, ${ }^{7,38}$ comorbidity and age were not found to have significant association with duration of hospitalisation. This is contrary to findings reported from Lagos State and China, which cited older patients as having significantly higher odds of being hospitalised for longer durations. ${ }^{7,38}$ In this study, less than $6 \%$ of the patients were aged above 59 years, perhaps accounting for the lack of association observed between age, comorbidity and duration of hospitalisation. There are therefore implications of our findings for further studies exploring patient's age, the duration of comorbidity, adherence to comorbidity treatment regimens and the extent of control and management in COVID-19 patients.

Almost all patients were discharged following management, contrary to many global reports that detail death rates between $15 \%$ and $37 \% .^{16,17,18}$ However, a report from the Zhejiang province of China just outside Wuhan, similarly reported discharge rates of $99 \%$. In that study, the median age reported (41 years) was close to the median age of our study (40 years). ${ }^{26}$ Younger population ages with lower prevalence of comorbidities have been proffered as likely reasons for comparatively low death rates observed in Africa.

\section{Strengths and limitations}

This study details information on a substantial number of COVID-19 cases managed in the early stage of the pandemic in Northern Nigeria and provides evidence that highlights the importance of COVID-19 preventive measures and policies. Furthermore, strengths of the study include a demonstration of factors that could be predictive of the presentation of COVID-19 symptoms in infected patients and the duration of hospitalisation of COVID-19 cases in Nigeria.

However, this study was subject to several limitations. Firstly, by studying only data from patients hospitalised and managed in the Asokoro Isolation and Treatment Centre in Abuja, the FCT, findings may not be generalisable to the entire country. Secondly, as a descriptive study, causal relationships cannot be clearly established. Also, there may have been some recall bias for symptoms and certain comorbidities in addition to social acceptability bias in patient reporting of certain lifestyle factors.

\section{Conclusion}

This study examines the demographic and clinical profiles of a cohort of COVID-19 patients managed at the Asokoro
COVID-19 Isolation and Treatment Facility in Abuja, the FCT, Nigeria. Less than $30 \%$ of the patients were asymptomatic and about $5 \%$ presented with a moderate to severe form of the disease. The commonest symptoms were cough, fever and fatigue and hypertension and diabetes mellitus were the most frequent comorbidities observed. Higher level of education was significantly associated with the presentation of symptoms in patients and daily alcohol intake was found to be significantly associated with the duration of hospitalisation.

These findings illuminate the importance of public education on risk factors and symptoms of the disease and lifestyle education to ensure early presentation, minimise illness and deaths from the infection, and optimise healthcare expenditure on the management of COVID-19.

\section{Acknowledgements}

The authors wish to express their sincere appreciation to the management of Federal Capital Territory (FCT) Health and Human Services Secretariat, FCT Department of Public Health, and Asokoro District Hospital for their commitment to quality patient care and a robust response in the face of the COVID-19 pandemic. Sincere thanks are extended to Dr Yetunde Obazee for her support during data collation.

\section{Competing interests}

The authors declare that they have no financial or personal relationships that may have inappropriately influenced them in writing this article.

\section{Authors' contributions}

I.O.A. and A.C.O. designed the study and analysed the data. I.O.A and A.C.O. discussed the results and wrote the article with input from all authors. All authors approved the final draft of the manuscript.

\section{Ethical considerations}

Ethical approval was obtained from the FCT Health Research Ethics Committee, with the assigned research protocol number: FHREC/2020/01/61/01-07-20 and date of validity from 1 July 2020.

\section{Funding information}

This research received no specific grant from any funding agency in the public, commercial or not-for-profit sectors.

\section{Data availability}

The authors confirm that the data supporting the findings of this study are available within the article.

\section{Disclaimer}

The views expressed in the submitted article are the authors' own and not an official position of the institutions. 


\section{References}

1. Worldometer. Coronavirus update (Live): $107,069,614$ cases and $2,338,174$ death from COVID-19 virus pandemic [homepage on the Internet]. No date [cited 2021 Feb 9]. Available from: https://www.worldometers.info/coronavirus/

2. Nigeria Centre for Disease Control (NCDC). Confirmed cases by State - NCDC coronavirus COVID-19 microsite. [homepage on the Internet]. 2021 [cited 2021 Feb 9]. Available from: https://covid19.ncdc.gov.ng/

3. Del Rio C, Malani PN. COVID-19 - New insights on a rapidly changing epidemic JAMA. 2020;323(14):1339-1340. https://doi.org/10.1001/jama.2020.3072

4. Li Q, Guan X, Wu P, et al. Early transmission dynamics in Wuhan, China, of novel coronavirus-infected pneumonia. N Engl J Med [serial online]. 2020 [cited 2021
Jan 7];382(13):1199-1207. Available from: https://www.nejm.org/doi/ Jull/10.1056/nejmoa2001316

5. Sohrabi C, Alsafi Z, O'Neill N, et al. World Health Organization declares global emergency: A review of the 2019 novel coronavirus (COVID-19). Int J Surg. 2020;76:71-76. https://doi.org/10.1016/j.ijsu.2020.03.036

6. Bowale A, Abayomi A, Idris J, et al. Clinical presentation, case management and outcomes for the first 32 COVID-19 patients in Nigeria. PAMJ. 2020;35(2):24 https://doi.org/10.11604/pamj.supp.2020.35.2.23262

7. Erinoso $\mathrm{O}$, Wright $\mathrm{K}$, Anya $\mathrm{S}$, et al. Clinical characteristics, predictors of symptomatic coronavirus disease 2019 and duration of hospitalisation in a cohor of 632 Patients in Lagos State, Nigeria. Niger Postgrad Med J. 2020;27(4):285 https://doi.org/10.4103/npmj.npmj_272_20

8. Otuonye NM, Olumade TJ, Ojetunde MM, et al. Clinical and demographic characteristics of COVID-19 patients in Lagos, Nigeria: A descriptive study. J Nat Med Assoc. 2020;in press. https://doi.org/10.1101/2020.09.15.20195412

9. National Population Commission (NPC) and The Demographic and Health Survey (DHS) Program. National population demographic and health survey 2018 [document on the Internet]. c2018 [cited 2021 Jan 7]. Available from: https:// dhsprogram.com/pubs/pdf/FR359/FR359.pdf

10. United Nations Department of Economic and Social Affairs, Population Division World population prospects 2019: Highlights, ST/ESA/SER.A/423 [document on the Internet]. c2019 [cited 2021 Jan 7]. Available from: https://population.un.org/ wpp/Publications/Files/WPP2019_Highlights.pdf

11. World Health Organization (WHO). Clinical management of COVID-19 (Interim guidance) [document on the Internet]. c2020 [cited 2021 Jan 7]. Available from: https://apps.who.int/iris/handle/10665/332196

12. World Health Organization (WHO). Criteria for releasing COVID-19 patients from isolation [document on the Internet]. c2020 [cited 2021 Jan 7]. Available from: isolation [document on the Internet]. c2020 [cited 2021 Jan 7]. Available from:
https://apps.who.int/iris/bitstream/handle/10665/332451/WHO-2019-nCoVhttps://apps.who.int/iris/bitstream/handle/10665/3

13. World Health Organization (WHO). Laboratory testing strategy recommendations for COVID-19 [document on the Internet]. c2020 [cited 2021 Jan 7]. Available from: https://apps.who.int/iris/bitstream/handle/10665/331509/WHO-COVIDfrom: htlab testing-2020.1-eng.pdf? sequence=1\&isAllowed=y

14. Nigeria Centre for Disease Control. COVID-19 situation reports - Number 154 [document on the Internet]. c2020 [cited 2021 Jan 18]. Available from: https:// ncdc.gov.ng/diseases/sitreps/?cat=14\&name $=$ An $\% 20$ update $\% 20$ of $\% 20$ COVID-19\%20outbreak\%20in\%20Nigeria

15. National Institutes of Health (NIH). COVID-19 treatment guidelines - Clinical spectrum of SARS-CoV-2 infection. [document on the Internet]. 2020 [cited 2021 Aug 14]. Available from: https://www.covid19treatmentguidelines.nih.gov/ overview/clinical-spectrum/

16. Docherty $A B$, Harrison EM, Green CA, et al. Features of 20,133 UK patients in hospital with covid-19 using the ISARIC WHO clinical characterisation protocol: Prospective observational cohort study. BMJ. 2020;369:m1985. https://doi. org/10.1136/bmj.m1985

17. Grasselli G, Zangrillo A, Zanella A, et al. Baseline characteristics and outcomes of 1591 patients infected with SARS-CoV-2 admitted to ICUs of the Lombardy region, Italy. JAMA [serial online]. 2020 [cited 2021 Jan 9];323(16):1574-1581. Available from: https://jamanetwork.com/journals/jama/fullarticle/2764365

18. Huang C, Wang Y, Li X, et al. Clinical features of patients infected with 2019 novel coronavirus in Wuhan, China. Lancet. 2020;395(10223):497-506. https://doi. org/10.1016/S0140-6736(20)30183-5

19. Lan FY, Wei CF, Hsu YT, et al. Work-related COVID-19 transmission in six Asian countries/areas: A follow-up study. PLoS One. 2020;15(5):e0233588. https://doi. org/10.1371/journal.pone.0233588

20. Agius RM, Robertson JFR, Kendrick D, et al. Covid-19 in the workplace. BMJ. 2020;370:m3577. https://doi.org/10.1136/bmj.m3577
21. Elimian $\mathrm{KO}$, Ochu $\mathrm{CL}$, llori E, et al. Descriptive epidemiology of coronavirus disease 2019 in Nigeria, February 27 - June 06, 2020. Epidemiol Infect [serial online]. 2020 [cited 2021 Jan 18];148:1-16. Available from: https://www.ncbi.nlm.nih.gov/ [cited 2021 Jan 18];148:1-16,
pmc/articles/PMC7506173/

22. European Centre for Disease Prevention and Control (ECDC). Heating, ventilation and air-conditioning systems in the context of COVID-19: First update changes to the current update [homepage on the Internet]. ECDC; 2020 [cited 2021 Jan 18]. Available from: https://www.ecdc.europa.eu/sites/default/files/documents/ Available from: https://www.ecdc.europa.eu/sites/default/files/documents/ update.pdf

23. Swärd P, Edsfeldt A, Reepalu A, et al. Age and sex differences in soluble ACE2 may give insights for COVID-19. Critical care. 2020;24:221. https://doi.org/10.1186/ s13054-020-02942-2

24. Patel SK, Velkoska E, Burrell LM. Emerging markers in cardiovascular disease: Where does angiotensin-converting enzyme 2 fit in? Clin Exp Pharmacol Physiol. 2013;40(8):551-559. https://doi.org/10.1111/1440-1681.12069

25. Yin G, Jin H. Comparison of transmissibility of coronavirus between symptomatic and asymptomatic patients: Reanalysis of the Ningbo COVID-19 data. JMIR Public Health Surveill. 2020;6(2):e19464. https://doi.org/10.2196/19464

26. Kim GU, Kim MJ, Ra SH, et al. Clinical characteristics of asymptomatic and symptomatic patients with mild COVID-19. Clin Microbiol Infect. 2020;26(7):948 e1-948.e3. https://doi.org/10.1016/j.cmi.2020.04.040

27. $X u X W, W u X X$, Jiang $X G$, et al. Clinical findings in a group of patients infected with the 2019 novel coronavirus (SARS-Cov-2) outside of Wuhan, China: Retrospective the 2019 novel coronavirus (SARS-Cov-2) outside of Wuhan, China: Retrospective from: https://pubmed.ncbi.nlm.nih.gov/32075786/

28. Rees EM, Nightingale ES, Jafari Y, et al. COVID-19 length of hospital stay: A systematic review and data synthesis. BMC Med. 2020;18:270. https://doi. org/10.1186/s12916-020-01726-3

29. National Health Commission \& State Administration of Traditional Chinese Medicine of the people's Republic of China. Chinese management guideline for COVID-19 (version 7.0) [homepage on the Internet]. NHC; 2020 [cited 2021 Aug 14]. Available from: https://www.chinadaily.com.cn/pdf/2020/1.Clinical.Protocols. for.the.Diagnosis.and.Treatment.of.COVID-19.V7.pdf

30. Nigeria Centre for Disease Control. National interim guidelines for clinical management of COVID-19 (version 3) [homepage on the Internet]. NCDC; 2020 [cited 2021 Aug 15]. Available from: https://covid19.ncdc.gov.ng/media/files/ National_Interim_Guidelines_for_Clinical_Management_of_COVID-19_v3.pdf

31. Bailey KL, Samuelson DR, Wyatt TA. Alcohol use disorder: A pre-existing condition for COVID-19? Alcohol. 2021;90:11-17. https://doi.org/10.1016/j.alcohol.2020.10.003

32. Skalny AV, Skalnaya MG, Grabeklis AR, et al. Zinc deficiency as a mediator of toxic effects of alcohol abuse. Eur J Nut. 2018 57:2313-2322. https://doi.org/10.1007/ s00394-017-1584-y

33. Oxford JS. Influenza a pandemics of the 20th century with special reference to 1918: Virology, pathology and epidemiology. Rev Med Virol. 2000;10(2):119-133.
https://doi.org/10.1002/(SICI)1099-1654(200003/04)10:2\%3C119::AIDhttps://doi.org/10.1002/
RMV272\%3E3.0.CO;2-O

34. Sugarman DE, Greenfield SF. Alcohol and COVID-19: How do we respond to this growing public health crisis? J Gen Int Med. 202036:214-215. https://doi. org/10.1002/(SICI)1099-1654(200003/04)10:2\%3C119::AID-RMV272\%3E3. org/ 10.1002

35. Miller J. Q\&A: COVID-19 pandemic threatens to exacerbate alcohol use disorder, risky behaviors. Healio [homepage on the Internet]. 2021 [cited 2021 Jan 15].
Available from: https://www.healio.com/news/primary-care/20201120/qacovid19-pandemic-threatens-to-exacerbate-alcohol-use-disorder-risky-behaviors

36. U.S Centers for Disease Control and Prevention (CDC). Obesity, race/ethnicity, and COVID-19 [document on the Internet]. 2021 [cited 2021 Jan 15]. Available from: https://www.cdc.gov/obesity/data/obesity-and-covid-19.html

37. Popkin BM, Du S, Green WD, et al. Individuals with obesity and COVID-19: A globa perspective on the epidemiology and biological relationships. Obes Rev. 2020;21(11):e13128. https://doi.org/10.1111/obr.13128

38. Guan W, Liang W, Zhao Y, et al. Comorbidity and its impact on 1590 patients with Covid-19 in China: A nationwide analysis. Eur Respir J [serial online]. 2020; in press [cited 2021 Jan 18]. Available from: https://erj.ersjournals.com/content/erj/ early/2020/03/17/13993003.00547-2020.full.pdf

39. US Centers for Disease Control and Prevention. National Center for health statistics adult tobacco use [document on the Internet]. 2019 [cited 2021 Aug 14]. Available from: https://www.cdc.gov/nchs/nhis/tobacco/tobacco_glossary.htm

40. US Department of Agriculture and US Department of Health and Human Services. Dietary guidelines for Americans, 2020-2025 [document on the Internet]. 9th ed.
2020 [cited 2021 Aug 14]. Available from: https://www.dietaryguidelines.gov/ sites/default/files/2020-12/Dietary_Guidelines_for_Americans_2020-2025.pdf 